http://journals.ums.ac.id/index.php/ijolae

\title{
Enhancing Critical Thinking in Analyzing Short Story "The Lazy Jack" Viewed from Identity Theory
}

\author{
Moh. Yamin ${ }^{1}$, Ajah Saputra ${ }^{2}$, Nurhamsi Deswila ${ }^{3}$ \\ ${ }^{1}$ Faculty of Education and Teacher Training, Universitas Lambung Mangkurat, Indonesia \\ ${ }^{2}$ Department of English Education, STKIP Muhammadiyah Sampit, Indonesia \\ ${ }^{3}$ Faculty of Education, Monash University, Australia
}

DOI: 10.23917/ijolae.v3i1.9948

Received: January $17^{\text {th }}, 2020$. Revised: April $8^{\text {th }}, 2020$. Accepted: April 10 ${ }^{\text {th }}, 2020$

Available Online: April $20^{\text {th }}, 2020$. Published Regularly: January $1^{\text {st }}, 2021$

\begin{abstract}
This paper aims to describe and discuss the messages and meanings of the short story "The Lazy Jack". The significance of this research is for building new frame that analyzing literary work is only viewed from the setting or character in a simple manner, but also can be viewed from identity theory assisted with critical thinking as the thinking approach rationally and based on the reason. The basis of reasoning is based on the researchers' capacity in deepening and learning the situations and conflict happening to the character in the story. It is qualitative research in which the data collection is started from coding obtained from the text "The Lazy Jack" in line with the goal of the research. The result of this research shows that Jack does not have a firm personal identity, firm life principle, life vision, and struggling for survival. He is the one dependent on others although he always fails to learn to be better. It means that Jack is without personal and social identity.
\end{abstract}

Keywords: critical thinking, identity theory, the lazy jack

Corresponding Author:

Moh. Yamin, Faculty of Education and Teacher Training, Universitas Lambung Mangkurat, Indonesia

E-mail: moh_yamin@ulm.ac.id

\section{Introduction}

Identity in literary work can be reflected

from the characters narrated in the story. Woodward (1997) stated that people's identity is reflected in the way they express their meaning and culture in their life. It can also be seen in the story in which the meaning and culture of the characters is explored. Identity exhibits how the characters appear in every part of the story. Identity theory should be viewed from understanding and explaining how social structures impact self; understanding and explaining how self impacts social behaviors. Identity can be constructed and/or highlighted by accessing both cultural and learned experiences to synthesize a given stimulus (Romagnoli, 2018).

In understanding that context, it is very necessary to get a detail explanation of how identity should be viewed to be able to comprehend and analyze the identity of characters in a story. It means that the first one, social roles are expectations attached to positions occupied in networks of relationships; identities are internalized role expectations. The second one, identity salience is defined as the probability that identity will be invoked across a variety of situations, or as the differential probability across persons that identity will be invoked in a given situation (Walker \& Lynn, 2013). 
What can be detail explanation is that model for identity theory is the identity standard or the set of (culturally prescribed) in which the meanings are held by the individual defining their role identity in a situation; perceptions by the person of meanings within the situation are matched to the dimensions of meaning in the identity standard (Stapleton, 2015).

Personality as identity is the other form explaining that identity should be viewed as the self-identity. In Freud's view, every per- sonality development is intervened by id, ego, and superego. The id is defined as the seat of drives and instincts (a throwback to the original drive model), whereas the ego represents the logical, reality-oriented part of the mind, and the superego is akin to conscience or set of moral guidelines and prohibitions (Britzman, 2012; Posey \& Cushing, 2019). All three help produce human personality (Liang, 2011). Here is the model used in the identity of the characters:

Table 1. Neo-Analytic Models of Personality

\begin{tabular}{|c|c|c|}
\hline Theorist & Key Assumption & Key Assumption \\
\hline Adler & $\begin{array}{l}\text { Family dynamics (especially birth or- } \\
\text { der) are the primary determinants of } \\
\text { personality. }\end{array}$ & Striving for superiority, inferiority complex \\
\hline Erikson & $\begin{array}{l}\text { Social interactions between individual } \\
\text { and significant others are key in perso- } \\
\text { nality development. }\end{array}$ & Psychosocial stages, developmental crises \\
\hline Fromm & $\begin{array}{l}\text { Personality is best understood concer- } \\
\text { ning prevailing social and political (as } \\
\text { well as intrapsychic) forces. }\end{array}$ & Authoritarianism \\
\hline Horney & $\begin{array}{l}\text { Infantile dependency-powerlessness is } \\
\text { key to personality. }\end{array}$ & Basic anxiety \\
\hline Jung & $\begin{array}{l}\text { Personality is shaped by spiritual forces } \\
\text { as well as by biological and social vari- } \\
\text { ables. }\end{array}$ & Archetypes, collective unconsciousness \\
\hline Sullivan & $\begin{array}{l}\text { Personality can only be conceptualized } \\
\text { within the context of an individual's } \\
\text { core relationships. }\end{array}$ & Personifications, developmental epochs \\
\hline
\end{tabular}

(Source: Britzman, 2012; Posey \& Cushing, 2019)

In understanding personal identity required to be able to show one's belief that through identity theory, it is very important what he or she thinks and says is believable to pay attention to critical thinking as a thinking framework so that identity theory used can be assisted with critical thinking existence. Critical thinking is evaluating whether we should be convinced that some claim is true or some argument is good, as well as formulating good arguments (Qablan et al, 2019). In critical thinking, anyone is and convincing.

Critical thinking is related to both deeper and higher-order thinking. It is a process of considering a topic or problem from multiple perspectives and focuses on achieving a particular outcome/resolution or simply to better understand all aspects of an issue. It may challenge established beliefs or prior 
knowledge and can provoke further questions or areas to explore/research (Bahr, 2010). It requires a deep knowledge that covers intellectual as well as humility (Paul, 1982 as cited in Mason 2008). It means that in critical thinking, the approach used in thinking should be based on the self capacity to participate in contextual meaning completed with prior knowledge. Consequently, there should be output gained from the thinking process. Thinking in critical thinking should be based on logical reason in which there should be started from thesis, antithesis, and synthesis (Limnatis, 2010).

Golding (2011) views critical thinking as a thinking-encouraging approach where it is important to scaffold students to think for themselves, rather than leading them to understand a body of knowledge. It is done, based on isolating and articulating critical thinking by 'reverse engineering' the questions expert critical thinkers ask. The result of using this method is that students will be immersed in the practice of making critical judgments where they will hone their critical skills, cultivate a critical character and begin to speak, act and think like expert critical thinkers. Therefore, cultivating critical thinking to students as an example is the description of how critical thinking should be practiced.

The fundamental purpose of the function of thinking is to attribute meaning to events in our lives, classify these events into categories and identify them subjectively. individuals who can effectively utilize critical thinking in their lives are individuals who possess the skills and disposition necessary for critical thinking. critical thinking is an important cognitive skill that affects students' viewpoints on events, their perceptions concerning what transpires in their environment and their decision-making processes (Tosuncuoglu, 2018). It means that critical thinking is needed as a thinking framework in responding to any issues or problems.

Because this paper was aimed to enhance critical thinking in analyzing the short story "The Lazy Jack" viewed from identity theory, so this concept was used to help identity theory in finding out the messages and meanings expressed in this kind of short story. The significance is that it gives a new perspective dealing with critical thinking combined with identity theory as the approach in analyzing literary work. Hopefully, its practice enriches the state of the art.

\section{Method}

It is qualitative research in which the research was conducted by taking the data from a short story entitled "The Lazy Jack", a story describing a character known as the lazy person. This research was based on describing the character as qualitative as possible so that all relevant data to explore the character was conducted as rigid as possible. Principally, it was based on the researcher's capability in explaining the data in a detailed manner. The character of lazy towards the character was illustrated as the one who never thinks before acting or deciding to do something. The subject of this research is the short story "The Lazy Jack" and the persons involved in this research are the researchers in which all data found were discussed critically.

In conducting the data collection, it was started from coding in which coding was functioned to sign every data considered important to note so that the data collection was rigidly done. Coding was done to make easy the next step that was called categorizing in which categorizing aimed to make sub-coding based on the data needed. 
Therefore, categorizing is a part of the coding done in data collection. Because the goal of the paper was oriented to obtain the messages and meanings expressed in the story, the data collection was focused on the paper goal. The data collected were interpreted based on the paper goal as the final step of coding. The coding used in this paper was manual coding (Saldana, 2013). Therefore, it used the researcher's knowledge in analyzing the text. Through critical thinking combined with identity theory as the knowledge capital, the researcher worked in analyzing the short story.

\section{Result and Discussion}

Jack describe in figure 1 is dominated by the id defined as the seat of drives and instincts (a throwback to the original drive model). This character does not show the effort to change lives better. His poor economy does not drive him to do change effort on what to do. He enjoys life and accepts the reality given although it does not contribute towards a better life.

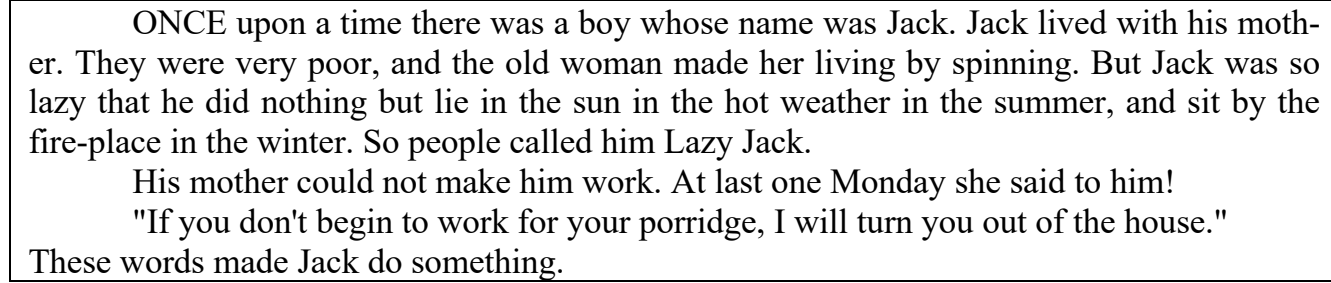

Figure 1. Jack with His Identity

Jack declares him as a child although he is not a child. The seat of drives and instincts embraces him so that he does not feel that he is not a child.

In Sigmund Freud's theory, he is in unconsciousness dealing with who he is and what he is (cf. Britzman, 2012). He is conscious after his mother threatens him. His consciousness appears because of external factors. Sullivan says that Jack's consciousness is conceptualized within the context of an individual's core relationships. Jung mentions that personality is shaped by spiritual forces as well as by biological and social variables. Jack as the person characterized as the lazy person appears not to do anything to change his behavior.

\footnotetext{
So on Tuesday, he went out and hired himself for a day to a neighboring farmer for a penny. But when he was going home in the evening, he lost the penny.

"You silly boy," said his mother, "you should have put it in your pocket."

"I'll do so another time." answered Jack.
}

Figure 2. Jack's First Experience

Jack, as shown in figure 2, is the one categorized hopeless identity. When rising, it is driven by id Horney includes him as the person with infantile dependency-powerlessness and in basic anxiety. He is not independent, not tough in struggling for life.

In identity theory usage, social roles are expectations attached to positions occupied in networks of relationships; identities are internalized role expectations (Jaspal \& Breakwell, 2014). Jack in this position is weak in interaction. He does not know what to do with the penny he holds. Jack is categorized as the person who is alone in his environment and never does the effort to make him better. Jack characterized as a hopeless person is an explanation that he does not have life vision of what to do. His 
identity is no identity. His identity reflects his zero knowledge of how to start to interact with the other. What Jack shows in his activity is his reflection on how he does life. It is meant that Jack is the one who does not know who he is actually.

On Wednesday, Jack went out again and hired himself to a cowman. The cowman gave him a jar of milk for his day's work. Jack took the jar of milk and put it into the large pocket of his jacket. But the milk was all spilled long before he got home.

"Oh! You should have carried it on your head," said the old woman. "I'll do so another time," answered Jack.

\section{Figure 3. Jack's Second Experience}

The same mistake foolish reappears towards Jack shown in figure 3 in which he does not know to differentiate the jar of milk and pocket. Again, he is mastered by the id, defined as the seat of drives and instincts (a throwback to the original drive model). What he sees is considered right to use although it is wrong. Britzman (2012) mentions that what Jack performs is a result of selfperception that he sees and considers right according to his perception. Therefore, the same mistake foolishly done by Jack is the reality of Jack's character.

This is in line with Eagly and Fine (2010) that attitudes do not exist in isolation from each other or other constructs. For example, people who favor social assistance payments to the poor may on average possess positive attitudes toward other social welfare programs such as national health care and subsidized housing. The positive attitudes toward all of these programs may, in turn, arise because the person attaches high importance to the social value of helpfulness. Such relations among attitudes and values may have implications for stability and change in attitudes. In this section, we consider how attitudes are structurally and functionally related to each other and how sets of attitudes may be related to higher-order constructs such as values and ideologies.

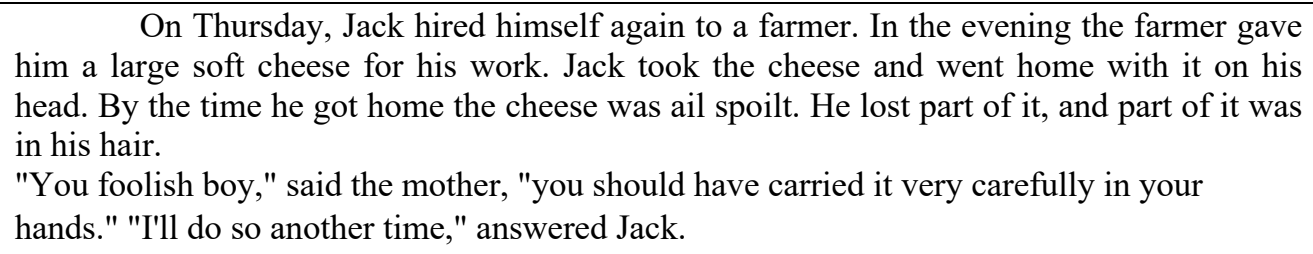

Figure 4. Jack's Third Experience

It is the same mistake in figure 4 that Jack is the kind of person who does not have independence and knowledge. In identity theory, Jack does not know how to use and what to use. Again, he is blank with what he faces. Id dominates his life. The thing to remember is that Jack seems not having the capacity to change his habit.

Jack is the one who is always busy with himself so that such a condition pushes him not to make him better in self personalization. Jack with his character that is not open with outside world teaching life dynamics causes him left behind in doing any adaptations and assimilations (Jaspal \& Breakwell, 2014).

Burke mentions the identity standard or the set of (culturally prescribed) meanings held by the individual defining their role identity in a situation. Jack, in this case, cannot position himself as the person he has to do. It is in line with what From (Bornstein, 
2003) says dealing with infantile dependency powerlessness and basic anxiety.

Jack is positioned as an unstable person because he psychologically does not have a principle in determining himself what to do.
Jack is anxious about what to do and how he thinks and acts. Consequently, he is in a bad situation in which Jack puts himself as the person in questioning.

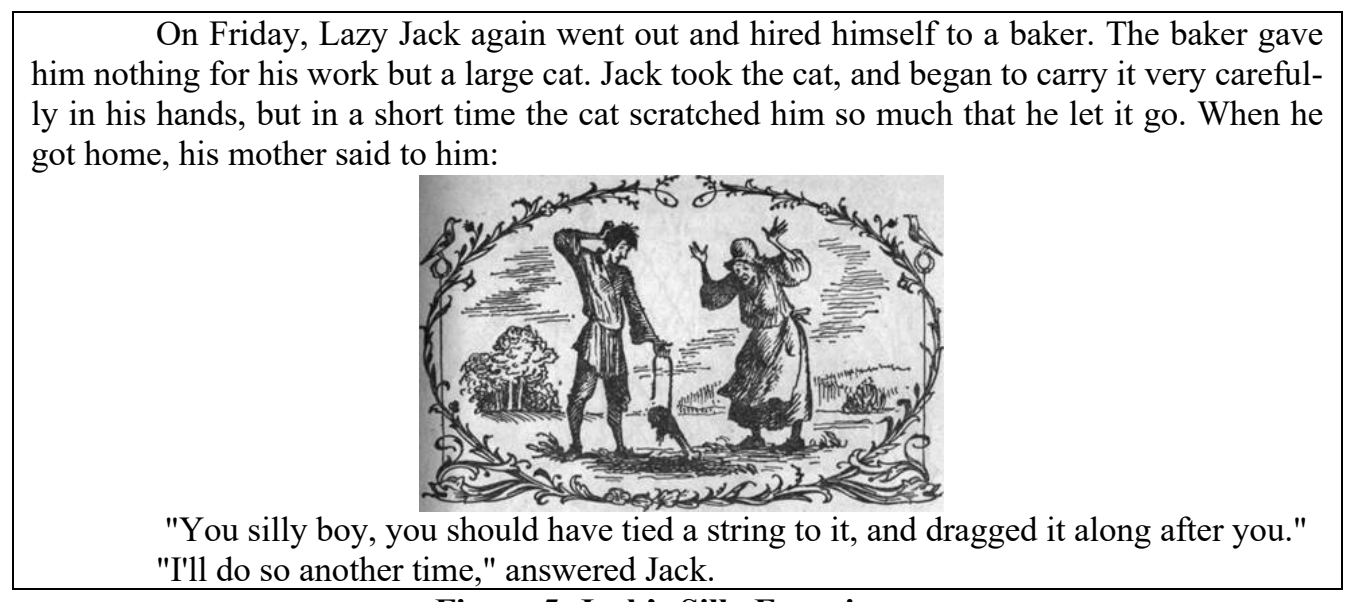

Figure 5. Jack's Silly Experience

Jaspal and Breakwell (2014) state that one's identity is determined based on how the person performs and interacts with others. One's identity is the reflection on who the one position himself to himself and others as a social creature. It means that in identity formation, there should be selfaffirmation that the one is stable in the psychological aspect so that this condition supports one's identity for himself and others. Jack in this context as the character in the story is told as the one who is undergoing an identity crisis in which he does not know what he does and how to do with anything happening to him.

Jack in figure 6 is blank what to do with the mutton he got from a butcher as the compensation. He considers mutton the thing tied and dragged. In his weak capacity dealing with mutton raw material, Jack is categorized as the person with Infantile dependencypowerlessness, basic anxiety. In Horney's view, his foolish act is a self-reflection that he is no identity (Bornstein, 2003).

\footnotetext{
On Saturday, Jack hired himself to a butcher, who gave him a shoulder of mutton for his work. Jack took the mutton, tied a string to it, and dragged it along after him. By the time he got home, the meat was quite spoilt.

This time his mother was very angry, for the next day was Sunday, and she had only cabbage for Sunday dinner.

"You foolish boy," said she to her son, "you should have carried it on your shoulder."

"I'll do so another time," answered Jack.
}

Figure 6. Jack's Foolish Experience

It is the irony for Jack in which he seems not to use his mind to be able to think logically. It means that Jack is Jack who is foolish because of his behavior not to learn from his mother's advice. He has undergone an identity crisis for himself as the person unstable.

Personal identity consists in nonbranching psychological connectedness and continuity. There is psychological connec- 
tedness when a person remembers doing or experiencing something that someone earlier did or experienced, or when a person's intention to do something leads to its later being done, or when psychological states, such as beliefs and desires, persist over time (Britzman, 2012).

What Britzman said means that Jack does not have a personal identity. Jack is not grouped in personal identity that has a goal and target in as much as whatever Jack does always creates anger from his mother. Every action Jack does makes his mother angry and disappointed so that this condition produces an identity crisis for Jack himself as the character narrated in the story. Jack has positioned meaningless towards himself illustrated in the story.

\section{On the next Monday, Lazy Jack again went out, and hired himself to a cattle keeper, who gave him a donkey for his work. Jack put the donkey on his shoulders and began to walk slowly home. \\ Now it happened that on his way home he passed the house of a rich man. This man had an only daughter, who was a beautiful girl, but she was deaf and dumb. She had never laughed in her life, and the doctors said she would never speak till somebody made} her laugh.

Figure 7. Jack's Unexpected Experience

In the second paragraph in figure 7 , it is said that Jack's foolish act is considered a lesson for the one with deaf and dumb. It is satire stating that only those with no brains will be successful persons. In other words, a dream comes true if it is reached through working hard and working with intelligence.

Erikson in Bornstein (2003) says that social interactions between individuals and others are key in personality development. Personality determines the high level of satisfaction of one's social interactions (Jamil, 2012). Jack seems not to have good interaction with other people so that he is not moti- vated to be a better person. He considers himself as the person who has enough knowledge of what to do although he always makes the same mistakes in everything that he does. So it appears that Jack lacks the satisfaction of social interaction with others.

It is also satire narrating Jack's act shown in figure 8 and it is said to be a lesson for the one with deaf and dumb to be able to hear and speak. It is only imagined identity teaching us to be human beings with ego and superego in order not to be laughed because of our strange and foolish acts.

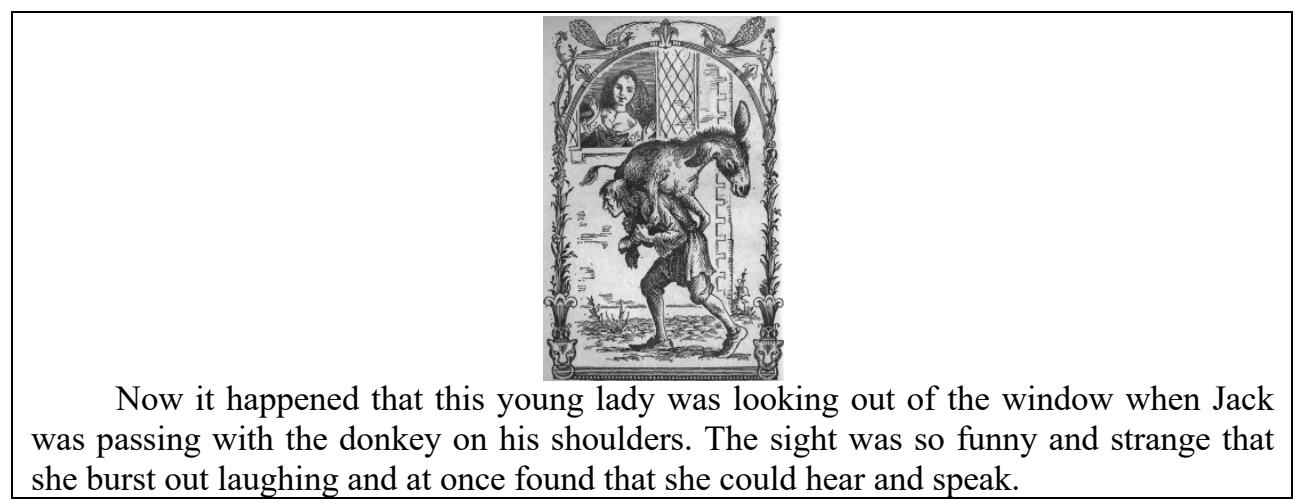

Figure 8. Jack's Funny Experince

What is shown in figure 8 is an describe the real thing. The foolishness imaginative example in which it does not behavior performed by Jack in a series of 
events teaches life wisdom. When Jack was passing with the donkey on his shoulders narrated in the story is called giving herb for the one with deaf and dumb to be able to hear and speak, it is the satire in which suggests not to be foolish like Jack in doing the life.

What is described in figure 8 is not the self-identity of Jack, but a failure in describing his identity as the person or character in the story. It is no matter that Jack is lazy, but it can be a problem in framing and building identity when Jack always puts himself as the person who never learns from the experience. Therefore, the self-identity of Jack does not represent his true self. What happens to Jack is explained by Jaspal and Breakwell (2014) that Jack in every series of actions in different situations never moves to be better in performing his behavior.

Based on all discussions from all findings, it is very important to use critical thinking in assisting identity theory in analyzing the literary work. Critical thinking used in analyzing short story "The Lazy Jack" through identity theory has contributed towards the deep analysis of the literary work. Therefore, Jack described in the story is the character without having a firm life principle, life vision, and struggling for survival. He is the one dependent on others although he always fails to learn to be better.

\section{Conclusion}

Jack based on his life story can be categorized as the person without an identity. His identity as a personal and social creature is doubtful because from every his life way from day to day told in the story, Jack always is the unlucky person. When he will be lucky, his luck is blocked by his foolish behavior and action. Jack is analogized as the character who never stops to do the same mistake and foolish although it harms him; other people laugh at and mock him.

\section{References}

Bahr, N. (2010). Thinking Critically about Critical Thinking in Higher Education. International Journal for the Scholarship of Teaching and Learning, 4(2).

https://doi.org/10.20429/ijsotl.2010.040 209

Bornstein, R. F. (2003). Psychodynamic Models of Personality. In M. J. Millon Theodore \& Lerner (Ed.), Handbook of Psychology. New Jersey: John Wiley \& Sons, Inc.

Britzman, D. P. (2012). What is the use of theory? A psychoanalytic discussion. Changing English: Studies in Culture and Education, 19(1), 43-56. https://doi.org/10.1080/1358684X.2012. 649143

Eagly, A., \& Fine, G. A. (2010). Bridging social psychologies: An introduction. Social Psychology Quarterly, 73(4), 313-315. https://doi.org/10.1177/0190272510391 422

Fatma Qablan, M. Ș. \& H. H. (2019). Critical Thinking in Education: the Case in Palestine. Turquoise International Journal of Educational Research and Social Studies, 1(1), 20-27.

Golding, C. (2011). Educating for critical thinking:

Thought-encouraging questions in a community of inquiry. Higher Education Research and Development, 30(3), 357-370. https://doi.org/10.1080/07294360.2010. 499144

Jamil, M. (2012). Satisfaction of Social Interaction On The Old Age With Personality Type. Jurnal Keperawatan, 171-182.

Jaspal, R. J., \& Breakwell, G. M. (Eds.). (2014). Identity Process Theory: Identity, Social Action and Social Change. Cambridge: Cambridge University Press. 
Liang, Y. (2011). The Id, Ego and Super-ego in Pride and Prejudice. International Education Studies, II(2), 177-181.

Limnatis, E. by N. G. (Ed.). (2010). The Dimensions of Hegel's Dialectic. New York: continuum. https://doi.org/10.1017/CBO978110741 5324.004

Mason, M. (Ed.). (2008). Critical thinking and learning. John Wiley \$ Sons, Incorporated. (pp Retrieved from https://ebookcentral.proquest.com

Posey, A. J., \& Cushing, J. (2019). Little Freudian Slippage: Coverage of the Psychodynamic Perspective in the Undergraduate Personality Course. Teaching of Psychology, 46(3), 251259.

https://doi.org/10.1177/0098628319853 941

Romagnoli, A. (2018). Sharing Identity: Indexing Cultural Perspectives through Writing Responses to Graphic Novels. SANE Journal: Sequential Art Narrative in Education, 2(3).

Saldana, J. (2013). The Coding Manual for Qualitative Researchers (2nd ed.).
London: SAGE.

Stapleton, S. R. (2015). Environmental identity development through social interactions, action, and recognition. Journal of Environmental Education, 46(2), 94-113. https://doi.org/10.1080/00958964.2014. 1000813

Stets, J. E., \& Burke, P. J. (2003). A sociological approach to self and identity. In M. L. and J. Tangney (Ed.), Handbook of Self and Identity (pp. 128152). Guilford Press. Retrieved from http://wat2146.ucr.edu/papers/02a.pdf

Tosuncuoglu, I. (2018). English language and literature students' perceptions of critical thinking. International Journal of Higher Education, 7(5), 20-28. https://doi.org/10.5430/ijhe.v7n5p20

Walker, M. H., \& Lynn, F. B. (2013). The Embedded Self: A Social Networks Approach to Identity Theory. Social Psychology Quarterly, 76(2), 151-179. https://doi.org/10.1177/0190272513482 929

Woodward, K. (Ed). (1997). Identity and difference (pp.8-12). London: Sage 